\title{
Retração acentual e verbos transitivos com leitura intransitiva
}

\author{
Raquel S. Santos \\ Universidade de São Paulo
}

\section{Abstract}

The focus of this paper is on the relation between syntax and prosody, by discussing the role of the empty syntactic categories in the application of the stress shift rule. The discussion about the influence of empty categories on phonological processes is not new. Usually, phonology papers argue that the access to syntax is indirect, and there is no access to phonological empty syntactic categories (cf. NESPOR; VOGEL, 1986). However, Santos (2002) argues that phonological empty syntactic categories can intervene on the rhythmic organization of utterances. She defends that pro intervene on stress shift rule, while trace is not taken into account for that rule. In order to show that, she tests utterances with stress clash between verb and adverb.

In this presentation, the syntactic structures with verbs which can have a transitive or intransitive reading are tested with pro. The hypothesis is that when there is a transitive reading, the stress clash can not be solved. In the sentences where the intransitive reading is possible, there is no pro between the verb and adverb, and the stress shift rule is allowed. This prediction can be used as an evidence which favors Galves (1989) analysis that null object in Brazilian Portuguese is a pro, and not a trace. 


\section{INTRODUÇÃO}

A discussão sobre a influência que os diversos componentes da gramática (fonologia, morfologia, sintaxe, semântica) 1 podem exercer entre si não é nova nos estudos lingüísticos e nem deixou de ser observada nas diferentes correntes teóricas. A grande questão é definir, para cada língua, quais elementos de um determinado componente $\mathrm{X}$ influenciam um componente Y. Uma vez que a influência ocorre, é plausível assumir que haja indícios da mesma; isto é, encontrar, em Y, indícios de que X é levado em conta.

A fonologia sempre foi um lugar onde a influência de outros componentes gramaticais é claramente apontada. Regras fonológicas segmentais fazem referência a fronteiras de morfemas ou de palavras. Regras como marcação de foco levam em conta informações semânticas e sintáticas. A acentuação depende da classe de palavras.

As explicações para a relação entre os diversos componentes gramaticais têm sido várias, e mais variadas ainda para os fenômenos ditos prosódicos. Chomsky \& Halle (1968) propõem que as regras fonológicas dependem dos tipos de fronteiras entre as palavras; Jaeggli (1980) argumenta que o traço formal de caso é considerado para a aplicação da regra de wanna-contraction, Kaisse (1985) defende que as regras fonológicas dependem exclusivamente de relações sintáticas - especificamente a relação de m-comando - entre os itens lexicais; Selkirk (1984) e Nespor \& Vogel (1986) argumentam que as regras fonológicas ocorrem em domínios prosódicos que são formados pela interação entre os diversos componentes da gramática.

Discutindo a resolução de choques acentuais, Frota (1995) e Abousalh (1997) defendem que esta resolução necessita da noção de domínios prosódicos, mas que também é sensível a estruturas sintáticas. Santos (2002) argumenta que a regra de retração acentual leva em conta estruturas sintáticas fonologicamente vazias (pro). 
Neste artigo, analiso como se comportam, em relação à retração acentual, as estruturas de sentenças simples formadas por verbos intransitivos, transitivos com leitura intransitiva, transitivos com objeto realizado, transitivos com objetos nulos e verbos que formam um predicado complexo. Além dos resultados sobre o comportamento fonológico dessas estruturas, esta análise traz evidências a favor da análise de Galves (1989) de que o objeto nulo, em português brasileiro, é um pro.

Este artigo está organizado da seguinte maneira: na seção 3 é discutida a proposta de Nespor \& Vogel para o mapeamento sintático e para retração acentual. A $4^{a}$. seção traz as propostas sintáticas para as categorias sintáticas vazias para o português. A $5^{\text {a }}$ seção trata dos cuidados metodológicos deste trabalho. Na seção 6 analisamos os dados, envolvendo categorias sintáticas vazias e aplicação de regras rítmicas. Finalmente, na seção 7 resumimos nossas observações.

\section{PRESSUPOSTOS TEÓRICOS}

Segundo Nespor \& Vogel (1986), as representações mentais da fala são organizadas hierarquicamente em constituintes prosódicos, que servem como domínio de aplicação de processos fonéticos e regras fonológicas. Alguns desses domínios são construídos levando em conta outros componentes gramaticais. No que diz respeito especificamente à sintaxe, Nespor \& Vogel afirmam haver duas hipóteses que consideram o acesso direto da fonologia. Na versão forte, todos os elementos foneticamente vazios (vestígio de NP, PRO, vestígio- $W h$, etc) teriam o mesmo status que itens lexicais com realização fonética e bloqueariam adjacência; já na versão mais fraca, apenas os elementos marcados por Caso seriam capazes de bloquear certas operações fonológicas. As autoras defendem que todos os casos discutidos na literatura podem ser analisados apenas com base na hierarquia prosódica, sem acesso às informações sintáticas e, por isso, defendem um acesso indireto aos outros componentes gramaticais; isto é, para a construção de um determinado domínio 
prosódico, leva-se em conta a informação de outros componentes. Uma vez construído esse domínio, não há mais acesso às informações dos outros componentes gramaticais. As autoras propõem sete níveis prosódicos, representados em (1) com os respectivos componentes gramaticais com que se relacionam:

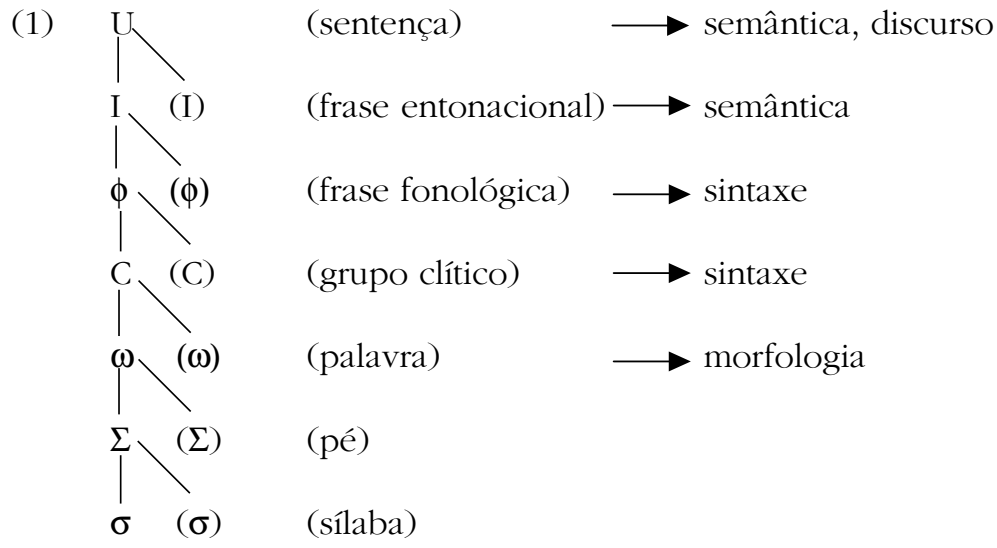

As operações fonológicas devem levar em conta o nível em que ocorrem. Outra distinção necessária é o local em que os processos fonológicos ocorrem. Há processos fonológicos que ocorrem em junturas de domínios, outros nas fronteiras do domínio, e por fim os que ocorrem no interior do domínio (SELKIRK, 1980, NESPOR \& VOGEL, 1986).

Frota (1995) e Abousalh (1997) argumentam que a retração acentual ocorre em f no português, tanto europeu quanto brasileiro, o que significa que leva em conta informações sintáticas. Segundo as autoras, trata-se de uma regra opcional, e muitas outras estratégias podem ser utilizadas com o mesmo intuito de eliminar a colisão acentual (pausa, alongamento, alternância de tons). As autoras também propõem que a retração acentual é uma regra que ocorre dentro dos domínios desse nível (e não nas fronteiras dos mesmos).

Nespor \& Vogel propõem o seguinte argumento para a construção dos domínios em $\phi$ : 
(2) $\phi$

I. $\phi$ domain: The domain of $\phi$ consists of a $C$ which contains a lexical head $(X)$ and all Cs on its nonrecursive side up to the $C$ that contains another bead outside the maximal projection of $X$.

II. $\phi$ construction: Join into an n-ary branching f all Cs included in a string delimited by the definition of the domain of $\phi$.

III. $\phi$ reestructuring (optional): a nonbranching $\phi$ which is the first complement of $X$ on its recursive side is joined into the $\phi$ that contains $X$.

De acordo com este algoritmo, uma sentença como "o José Maria comeu bolo" deve ter os seguintes domínios: ${ }^{1}$

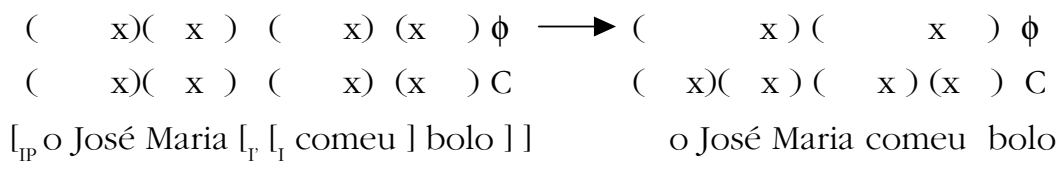

Santos (2002), no entanto, defende que, mesmo depois de formados os domínios, a fonologia tem acesso a informações sintáticas. Os argumentos da autora são baseados no fato de que as duas sentenças abaixo (4) e (5) devem ter a mesma configuração dos domínios, dado o algoritmo de Nespor \& Vogel e, no entanto, só a sentença (4) permite a retração acentual: ${ }^{2}$

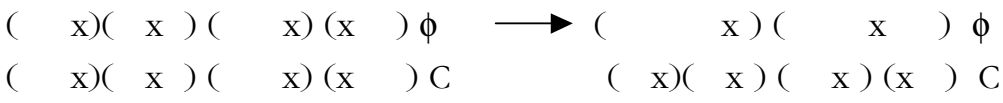

o José Maria canTOU HOje

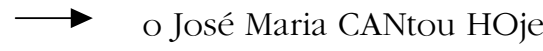

o José Maria conTOU HOje

$\longrightarrow \quad$ \# o José Maria CONtou HOje

Segundo Santos, a impossibilidade de retração acentual em (5) deve-se ao fato de que, entre o verbo e o advérbio, ocorre um pro. Assim, o que parece ser uma adjacência acentual na realidade não o é, pois há um pro entre o verbo e o advérbio na sentença (5).

No entanto, Santos (2002) não analisou sentenças simples com objetos nulos. Sua análise baseou-se em sentenças com ilhas e sentenças simples com foco ou tópico, de forma a garantir que o objeto nulo não seria movido para uma posição mais alta na estrutura sintática. 
Sentenças com ilha impedem o movimento do objeto para fora das mesmas. Uma sentença com ilha e foco é gramaticalmente ruim, o que indica que o foco é resultado de movimento (6a) e há um vestígio preenchendo a posição de objeto (6b). Por outro lado, sentenças com ilha e tópico são boas, o que indica que a estrutura de tópico foi gerada in situ ( $7 \mathrm{a})$ e que há um pro preenchendo a posição de objeto (7b):

(6a) * [só esse livro] $]_{\text {Foco }}$ eu tive a confirmação [ de que o Carlos perdeu _ hoje] (6b) * [só esse livro] ${ }_{\mathrm{FOCO}}$ eu tive a confirmação [ de que o Carlos perdeu $t$ hoje] (7a) [esse cargo $]_{\text {TOP }}$ eu tive a confirmação [ de que o Carlos perdeu _ ontem] (7b) [esse cargo $]_{\mathrm{TOP}}$ eu tive a confirmação [ de que o Carlos perdeu pro ontem]

A sentença (7b) pode ser testada quanto à retração acentual, pois é uma sentença gramaticalmente bem formada. Esse tipo de sentença não permite a retração acentual, indicando que pro é considerado pela regra de resolução de encontro (8):

(8) \# esse cargo eu tive a confirmação [ de que o Carlos PERdeu pro ONtem]

As sentenças com ilha e foco não podem ser testadas fonologicamente porque já são gramaticalmente ruins. No entanto, sabendo que foco envolve movimento, é possível testar sentenças simples com foco e observar que a retração acentual pode ocorrer (9):

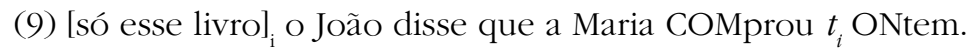

\section{PROPOSTAS SINTÁTICAS PARA O OBJETO NULO EM PORTUGUÊS}

As propostas de análise para o objeto nulo em português não são concordes. Raposo (1986), baseado na inaceitabilidade de sentenças contendo objeto nulo dentro de ilhas (10 e 11), propôs que este é um vestígio, resultado de movimento. Em Raposo (1998), o autor modifica sua proposta e assume que, tanto para o português europeu quanto para o português brasileiro, o objeto nulo é uma categoria mista, um DP com D nulo e complemento pro, que se 
move para foco. As duas propostas assumem movimento, o que significa que uma sentença como (5) deve ser analisada como em (12): (10) * O rapaz que trouxe _ mesmo agora da padaria era o teu afilhado. (11) * Que a IBM venda _ a particulares surpreende-me.

(12) $\mathrm{OP}_{\mathrm{i}}$ o josé maria conTOU $t_{i}$ HOje.

As análises sobre o português brasileiro, no entanto, mostram que muitas sentenças consideradas agramaticais para o português europeu são aceitáveis para o português brasileiro (cf. GALVES, 1989, KATO, 1993, CYRINO, 1994, FERREIRA, 2000, RAPOSO \& KATO, 2001). Nessa língua, as sentenças (10) e (11) são plenamente aceitáveis. Galves (1989) propõe que o objeto nulo em português brasileiro é um pro gerado na base e ligado a um sujeito externo, não precisando de um operador nulo para ser licenciado. ${ }^{3}$ De acordo com essa análise, a representação da sentença (5) em PB deve ser como em (13), e não como em (12):

(13) o José Maria conTOU pro HOje.

Essencialmente, as duas propostas divergem quanto a considerar o objeto nulo como um vestígio ou como pro. Uma vez que Santos (2002) mostrou que essas categorias vazias comportam-se diferentemente quando da aplicação da regra de resolução de encontro acentual, a possibilidade ou não de aplicação dessa regra constitui evidência externa para uma ou outra análise do objeto nulo em português.

\section{METODOLOGIA}

Para este trabalho, foi constituído um corpus de 28 sentenças em que se testou a possibilidade de retração acentual com 4 falantes do português brasileiro, resultando em 112 sentenças. Os testes foram perceptuais. ${ }^{4}$ As sentenças eram lidas pelo pesquisador e os informantes deveriam dizer se a retração era possível ou não.

Uma vez que o interesse era observar se os tipos de verbos influenciariam a possibilidade de retração acentual, cada sentença 
do corpus era a resposta para uma pergunta que se inseria numa situação descrita. Assim, foram controladas as diversas possíveis leituras que os verbos poderiam ter. Abaixo, seguem-se exemplos das sentenças do corpus com a classificação dos verbos. ${ }^{5}$

\section{Intransitivo}

(14) a Maria Clara saiu hoje.

\section{Transitivo com leitura intransitiva}

Situação: a Maria Clara sofre de anorexia. A mãe, preocupada, liga para a empregada e pergunta:

Q: quando foi a última vez que a Maria Clara comeu?

(15) a Maria Clara comeu hoje, não se preocupe.

\section{Transitivo com objeto nulo}

Q: quando a Maria Clara comeu aquela torta suíça que estava na geladeira? (16) a Maria Clara comeu hoje.

\section{Transitivo com objeto realizado}

Q: quando a Maria Clara comeu aquela torta suíça que estava na geladeira? (17) a torta suíça de chocolate, a Maria Clara comeu hoje.

\section{Predicado complexo}

Q: a Maria Clara comeu feijão?

(18) a Maria Clara comeu hoje

Alguns cuidados metodológicos foram tomados para a construção das sentenças-teste. O primeiro deles diz respeito à quantidade de sílabas do verbo. De acordo com as propostas sobre regra rítmica, no caso de retração acentual, o primeiro acento do encontro movese para a esquerda, para a primeira sílaba portadora de acento no nível inferior. Se a palavra tiver mais do que duas sílabas pré-tônicas, essa retração fará com que o acento se mova para a sílaba portadora do acento secundário, como é possível observar em (19): 
(19)

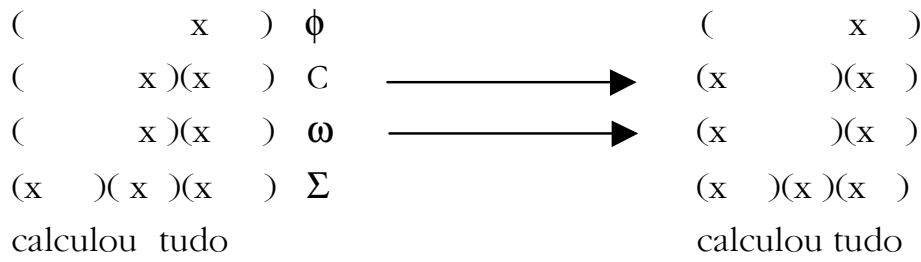

Quando a regra de resolução acentual ocorre com verbos dissílabos, a retração do primeiro acento faz com que este recaia sobre a primeira sílaba da palavra, que é mais fraca, como pode ser observado em (20): ${ }^{6}$

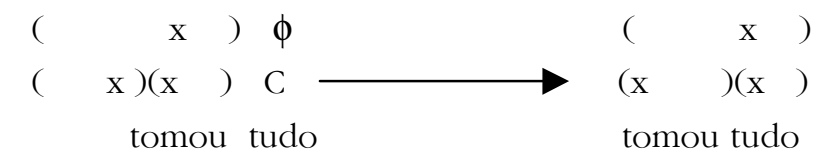

Um segundo cuidado com as sentenças testadas foi que os fs formados por reestruturação tivessem o mesmo tamanho. Sandalo \& Truckenbrodt (2002) argumentam que a retração acentual é bloqueada quando as frases fonológicas são de tamanho diferente, como é possível observar abaixo: ${ }^{7}$

(21) (CAfé QUENte) (queima a boca).

(22) \# (CAfé QUENte) (queima).

\section{ANÁLISE DOS DADOS}

As sentenças foram ouvidas por quatro informantes. Os julgamentos sobre a possibilidade de aplicação da regra de retração acentual estão organizados na tabela em (23) de acordo com o número da sentença-teste:8,9 
(23)

\begin{tabular}{|c|c|c|c|c|c|c|c|c|c|c|c|c|c|c|c|c|c|c|c|}
\hline \multicolumn{5}{|c|}{$\begin{array}{l}\text { Verbos com } \\
\text { leitura intransitiva }\end{array}$} & \multicolumn{5}{|c|}{$\begin{array}{l}\text { Verbos transitivos } \\
\text { com objeto realizado }\end{array}$} & \multicolumn{5}{|c|}{$\begin{array}{l}\text { Verbos transitivos } \\
\text { com objeto nulo }\end{array}$} & \multicolumn{5}{|c|}{$\begin{array}{l}\text { Predicados } \\
\text { complexos }\end{array}$} \\
\hline 3 & ap & ap & ap & ap & 2 & ap & ap & ap & ap & 1 & bk & bk & bk & bk & 17 & ap & ap & bk & bk \\
\hline 6 & ap & bk & ap & ap & 5 & ap & ap & ap & ap & 4 & bk & $\mathrm{bk}$ & bk & bk & 18 & bk & ap & ap & ap \\
\hline 9 & ap & ap & ap & ap & 8 & ap & ap & ap & ap & 7 & bk & bk & bk & bk & 19 & ap & ap & bk & ap \\
\hline 13 & ap & ap & ap & ap & 14 & ap & ap & ap & ap & 10 & bk & bk & bk & bk & 23 & ?? & ap & ap & bk \\
\hline 20 & ap & ap & ap & ap & 16 & bk & ap & ap & ap & 11 & bk & bk & bk & bk & 26 & ap & ap & ap & ap \\
\hline 21 & ?? & ap & ?? & ap & 24 & ap & ap & ap & ap & 12 & bk & bk & bk & bk & 27 & ap & ap & ap & ap \\
\hline 22 & bk & ap & ap & ap & 25 & ap & ap & ap & ap & 15 & bk & bk & bk & bk & 28 & ?? & ap & ap & ap \\
\hline
\end{tabular}

Como apresentado na seção 2, segundo Santos (2002), a retração acentual é opcional e sensível a categorias sintáticas foneticamente vazias. No caso de um encontro acentual entre verbo e advérbio, a retração do primeiro acento para a sílaba anterior é possível se a categoria vazia é um vestígio de movimento, mas não se é um pronome nulo (pro).

As sentenças aqui analisadas são sentenças simples, e a possibilidade de retração acentual em sentenças com verbos transitivos e objeto nulo indicaria que o objeto nulo se moveu para uma posição mais alta, deixando um vestígio entre o verbo e o advérbio, como em (24a). Por outro lado, a impossibilidade pode ser devida ao pro preenchendo a posição de objeto (24b) ou à opcionalidade da regra:

(24a) OP o José Maria contou $t$ hoje.

(24b) o José Maria contou pro hoje.

Os resultados encontrados neste trabalho apontam para o fato de que a retração é sempre bloqueada nos casos de leitura transitiva com objeto nulo em sentenças simples. Deve-se ter em mente que a regra de retração acentual é uma regra opcional, e por isso o bloqueio não é prova de que haja um pro entre verbo e advérbio; o fato de poder ser um vestígio e ainda assim a escolha por não se aplicar a regra deve ser considerado. Procurou-se testar as sentenças observando se fronteiras do nível entonacional ou de sentença poderiam estar influenciando a retração e, perceptualmente, tal fato não foi relevante para os informantes. ${ }^{10}$ 
Para todos as outras estruturas verbais a retração foi possível, mas para a leitura transitiva com objeto nulo, o bloqueio foi categórico. Se estivéssemos frente ao caso de opcionalidade da regra, este bloqueio não deveria ser categórico, deveríamos ter encontrado variação e possibilidade de aplicação da regra. Tal fato é uma evidência a favor da análise de Galves para o PB de que o objeto nulo é um pro não coindexado e não se move para posições mais altas da estrutura em sentenças simples.

Outro grupo de verbos testados foram os verbos com leitura transitiva e objeto realizado. Este grupo foi utilizado como controle para o grupo anterior. Os dados com verbos transitivos com objeto realizado indicam que há um movimento do objeto, deixando um vestígio. O vestígio não é enxergado pela operação de retração acentual e o encontro acentual pode ser desfeito, como é possível observar em (25):

(25 (sentença-teste 2$)$ )

$$
\begin{aligned}
& \left(\begin{array}{lllll}
\mathrm{x} & & (\mathrm{x}
\end{array}\right)\left(\begin{array}{lll}
\mathrm{x} &
\end{array}\right) \phi_{\text {reestruturado }} \\
& \left(\begin{array}{lll}
\mathrm{x} & )( & \mathrm{x}
\end{array}\right)\left(\begin{array}{l}
\mathrm{x}
\end{array}\right)\left(\begin{array}{l}
\mathrm{x}
\end{array}\right)(\mathrm{x}) \mathrm{C} \\
& \text { a água }{ }_{i} \text { a Maria Clara BEbeu } t_{i} \text { CEdo }
\end{aligned}
$$

Uma vez que a retração acentual é opcional, é possível haver o bloqueio, como ocorre em (16). Esses resultados confirmam os encontrados por Santos (2002) para sentenças simples em que o objeto se move para a posição de tópico e deixa um vestígio na posição abaixo.

Os dados com leitura intransitiva mostram que a retração acentual é permitida, o que indica que não há nada intervindo entre o verbo e o advérbio, como em (27).

(27 (sentença-teste 3))

$(\mathrm{x})$
$(\mathrm{x})(\mathrm{x})(\mathrm{x})(\mathrm{x})$

a Maria Clara BEbeu HOje 
Nos casos de verbos intransitivos, esses dados são compatíveis com a proposta de Hale \& Keyser (1993) de que os verbos intransitivos puros são formados por argumentos incorporados que deixam vestígio, como representado em (28).

(28) a Maria Clara 'deu (tomou) uma bebida' hoje.

a Maria Clara bebeu hoje.

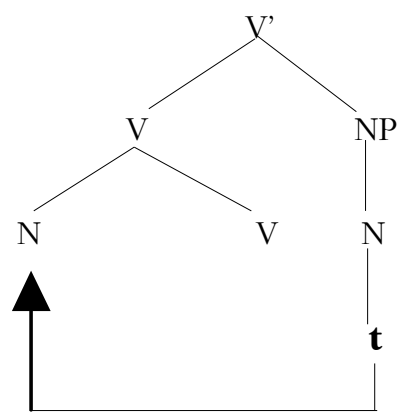

As sentenças 17 e 18 são formadas por verbos que formam um predicado complexo, o que explica a variação nos julgamentos. "jogar bola” tem uma interpretação já lexicalizada e o nome 'bola' não é um complemento do verbo 'jogar', tanto que não é possível acrescentar um complemento ao nome 'bola' (ao contrário de 'jogar a bola', em que 'a bola' é complemento de 'jogar'), como é possível observar no contraste entre (29a), um predicado complexo, e (29b), um verbo e complemento:

(29a) * jogar bola verde

(29b) jogar a bola verde

Nestes casos, por ser um predicado complexo, não há nem objeto nulo nem vestígio entre o verbo e o advérbio, e o encontro acentual pode ser desfeito, como em (30):

(30 (sentença-teste15))

Q: quando a Maria Clara jogou bola?

a Maria Clara JOgou TERça depois do almoço. 


\section{CONSIDERAÇÕES FINAIS}

Os resultados encontrados neste trabalho corroboram certas propostas teóricas que podem ser considerados como evidências no caso de mais de uma proposta. Outro fator importante diz respeito à discussão sobre o acesso a outros componentes gramaticais.

Observou-se que, no caso de sentenças simples com objetos nulos em português brasileiro, os dados indicam que a análise de Galves, que assume que o objeto nulo em português brasileiro é um pro in situ, é mais acertada do que a de Raposo, que considera o objeto nulo o resultado de movimento. No que se refere a verbos transitivos com leitura intransitiva, esta análise é compatível com Hale \& Keyser para verbos intransitivos. No caso de predicados complexos, os resultados são compatíveis com a interpretação lexicalizada dos mesmos.

Os resultados encontrados para os diversos tipos de objetos apontam para a distinção entre as duas categorias vazias pro e vestígio. Nespor \& Vogel afirmam que uma versão forte da hipótese de acesso direto da fonologia à sintaxe é que todos os elementos foneticamente vazios (vestígio de $\mathrm{NP}, \mathrm{PRO}$, vestígio- $W$, etc) teriam o mesmo status que itens lexicais com realização fonética e bloqueariam adjacência. Neste caso, vestígio e pro deveriam provocar os mesmos resultados. No entanto, se assumimos a proposta de Chomsky (1995) de que vestígios são cópias apagadas, a distinção entre pro e vestígio torna-se clara. Vestígio passa a ser uma notação em lugar de onde foi copiada uma categoria, mas não há nada naquele lugar da estrutura. Assim, em uma sentença em que o objeto foi movido, não há nada entre o verbo e o advérbio, o que cria a adjacência acentual a ser resolvida. Essa invisibilidade de vestígios descrita acima nos leva a concluir que o apagamento de cópias se dá antes que o acento seja computado. Essa conclusão é compatível com a proposta de Nunes $(1995,1999)$, de acordo com a qual cópias são apagadas no componente fonológico para permitir que a estrutura sintática seja linearizada de acordo com o Axioma de Correspondência Linear de Kayne (1994). 


\section{NOTAS}

${ }^{1}$ Apresento apenas os domínios de $\phi$ e C, relevantes para a discussão sobre a retração acentual.

${ }^{2}$ Para indicar a impossibilidade de retração acentual, uso \#. As maiúsculas são utilizadas para marcar a sílaba acentuada.

${ }^{3}$ Para diferentes análises da ausência de efeitos de ilha em construções com objeto nulo em PB, ver, entre outros, Kato (1993), Cyrino (1994) e Ferreira (2000).

${ }^{4}$ Para a continuação deste trabalho, pretende-se fazer uma análise acústica das sentenças analisadas. A discussão sobre a realização da retração acentual realmente ocorrer ou ser uma impressão não é nova. Barbosa e Madureira, em suas apresentações neste Seminário, questionam a realização fonética da retração acentual. É claro, no entanto, para os informantes, que há um movimento acentual da primeira sílaba envolvida no encontro de acentos.

${ }^{5}$ As sentenças utilizadas no teste estão no Apêndice, ao final do texto.

${ }^{6}$ A literatura não é consensual sobre a formação de pés nestes casos. Propostas como a de Nespor \& Vogel (1986) e Selkirk (1984) consideram que a primeira sílaba forma um pé degenerado. Sandalo (comunicação pessoal) aponta que também é possível a criação de um iambo.

${ }^{7}$ Os exemplos são de Sandalo (2002). Para uma discussão pormenorizada de sua proposta, veja o texto neste mesmo volume, e Sandalo \& Truckenbrodt (2002).

${ }^{8}$ ap para possibilidade, $b k$ para bloqueio, ?? para dúvidas.

${ }^{9}$ As sentenças 3, 6, 9, 13 são formadas por verbos transitivos com leitura intransitiva. As sentenças 20, 21, 22 são formadas por verbos intransitivos puros.

${ }^{10}$ Como dito em nota anterior, um próximo passo deste trabalho será fazer uma análise acústica das sentenças.

\section{REFERÊNCIAS BIBLIOGRÁFICAS}

ABOUSALAH, E. S. F. Resolução de choques de acento no português brasileiro: elementos para uma reflexão sobre a interface fonologia-sintaxe. 1997. Dissertação (Mestrado) - Universidade Estadual de Campinas.

CHOMSKY, N. The minimalist program. Cambridge, Mass: The MIT Press, 1995 CHOMSKY, N.; HALLE, M. The sound pattern of English. New York: Harper and Row, 1968 
CYRINO, S. O objeto nulo no português do Brasil-um estudo sintático-diacrônico. 1994. Tese (Doutorado) - Universidade Estadual de Campinas.

FERREIRA, M. B. Argumentos nulos em português brasileiro. 2000. Dissertação (Mestrado) - Universidade Estadual de Campinas.

FROTA, S. Clashes and prosodic domains in European Portuguese. IFA Proceedings, n. 19, p. 93-107, 1995.

GALVES, C. O objeto nulo no português brasileiro: percurso de uma pesquisa. Cadernos de Estudos Lingüísticos, n. 17, p. 65-90, 1989.

HALE, K.; KEYSER, S. J. On Argument structure and the lexical expression of syntactic relations. In: HALE, K.; KEYSER, S. J. (Ed.). The view from Building 20 - essays in linguistics in bonor of Sylvain Bromberger. Cambridge, Mass: MIT Press, 1993.

JAEGGLI, O. Remarks on To contraction. Linguistic Inquiry, n. 11, v. 1, p. 239$245,1980$.

KAISSE, E. M. Connected Speech - the Interaction of Syntax and Phonology. Florida: Academic Press, Inc., 1985.

KATO, M. A. Recontando a história das relativas em uma perspectiva paramétrica. In: ROBERTS, I.; KATO, M. A. (Org.). Português brasileiro - uma viagem diacrônica. Campinas: Ed. Unicamp, 1993.

KATO, M. A.; RAPOSO, E. O objeto nulo definido no português europeu e no português brasileiro: convergências e divergências. In: CORREIA, C.; GONÇALVES, A. (Ed.). Actas do XVI Encontro Nacional da Associação Portuguesa de Linguística APL. Lisboa, 2001.

KAYNE, R. The antisymmetry of syntax. Cambridge, Mass: The MIT Press, 1994. NESPOR, M.; VOGEL, I. Prosodic phonology. Foris: Dordrecht, 1986.

NUNES, J. M. The copy theory of movement and linearization of chains in the Minimalist Program. 1995. Tese (Doutorado) - Universidade de Maryland, College Park.

NUNES, J. M. Linearization of chains and phonetic realization of chain links. In: EPSTEIN, S.; HORNSTEIN, N. (Ed.). Working minimalism. Cambridge, Mass: The MIT Press, 1999.

RAPOSO, E. On the null object in European Portuguese. In: JAEGGLI, O.; CORVALAN, C. S. (Ed.). Studies in romance linguistics. Foris: Dordrecht, 1986. 
RAPOSO, E. Definite/zero alternations in Portuguese. In: SCHWEGLER, A.; TRANEL, B.; URIBE-ETXEBARRIA, M. (Ed.). Romance Linguistics: Theoretical Perspectivess. Amsterdam, John Benjamins, 1998.

SANTOS, R. S. Categorias sintáticas vazias e retração de acento em português brasileiro. DELTA, n. 18, v. 1, p. 67-89, 2002.

SANDALO, F. Fonologia Prosódica e Teoria da Otimidade: reflexões sobre a interface sintaxe e fonologia na formação de sintagmas fonológicos. Comunicação apresentação no I Congresso Internacional/ VII Congresso Nacional de Fonética e Fonologia. Belo Horizonte: UFMG, 2002.

SANDALO, F.; TRUCKENBRODT, H. Some notes on phonological phrasing in Brazilian Portuguese. In: CSIRMAZ, A.; LI, Z.; NEVINS, A.; VAYSMAN, O.; WAGNER, M. (Ed.). Phonological Answers: MIT Working Papers in Linguistics, $\mathrm{n}$. 42, p. 285-310, 2002.

SELKIRK, E. O. The role of prosodic categories in English word stress. Linguistic Inquiry, n. 11, p. 563-605, 1980.

SELKIRK, E. O. Phonology and syntax: the relation between sound and structure. Cambridge, Mass: The MIT Press, 1984. 


\section{APÊNDICE:}

Abaixo seguem-se todas as sentenças testadas com os contextos utilizados, de modo a elucidar a leitura do verbo que se pretendia testar. As sentenças estão organizadas pelos verbos utilizados, independente de sua leitura.

situação: a Maria Clara precisa beber no mínimo 2 litros de água por dia para seus rins funcionarem. A mãe chega do trabalho, pergunta e a irmã responde: Q: Quando a MC bebeu a água dela?

1) a Maria Clara BEbeu CEdo, logo que você saiu

2) a água, a Maria Clara BEbeu CEdo, logo que você saiu.

situação: a Maria Claria tem um problema com bebidas, tem mania de se embebedar. A mãe chega de viagem, pergunta e a irmã responde:

Q: quando foi a última vez que a Maria Clara bebeu? (ser beberrona)

3) a Maria Clara BEbeu HOje, depois de você sair.

situação: a Maria Clara precisar tomar um remédio na hora certa, pra não ter problemas de saúde. A mãe chega do trabalho, pergunta e a irmã responde:

Q: Quando a MC bebeu o remédio que estava em cima da mesa?

4) a Maria Clara BEbeu HOje, depois que eu cheguei.

5) o remédio, a Maria Clara BEbeu HOje, quando eu saí.

situação: a Maria Clara tem câncer de pulmão. A mãe chega de viagem e pergunta, a irmã responde:

Q: quando foi a última vez que a Maria Clara fumou? (ser fumante)

6) a Maria Clara fumou hoje, logo antes de você chegar.

situação:a Maria Clara adora fumar cachimbo e sua mãe detesta esse hábito, pois acha que cachimbo é coisa de homem. A mãe chega de viagem, pergunta e a irmã responde:

Q: Quando foi a última vez que a MC fumou o cachimbo do pai?

7) a Maria Clara FUmou HOje, logo antes de você chegar.

8) o cachimbo do papai, a Maria Clara FUmou HOje, escondido de mim.

situação: a Maria Clara foi ao shopping para fazer várias compras. O marido foi levá-la e ficou esperando no estacionamento. Ele vira para o amigo e diz: 9) a maria clara COMprou RÁpido hoje. (fez as compras rápido)

situação: a Maria Clara compra bilhetes de loteria todos os dias, com esperança de ganhar na sena. O marido foi levá-la e ficou esperando no estacionamento. Ele vira para o amigo e diz:

10) a Maria Clara COMprou RÁpido hoje. 
situação: um homem está conversando com seu amigo sobre as compras de natal. O amigo diz que a esposa irá fazer compras no sábado e ele responde:

11) a Maria Clara COMprou HOje mesmo, pra evitar tumulto no shopping.

situação: um homem está conversando com seu amigo sobre o carro novo que a Maria Clara quer comprar. O amigo diz que a esposa irá comprar um no sábado e ele responde:

12) a Maria Clara COMprou HOje, porque não podia ficar sem carros.

situação: um homem está conversando com seu amigo sobre as compras de natal. O amigo diz que a esposa irá fazer compras no sábado e ele responde:

13) a Maria Clara COMprou CEdo este ano, antes de todo mundo.

situação: um homem está conversando com seu amigo sobre um boné comemorativo da seleção. O amigo diz que não conseguiu comprar, pois estavam todos vendidos. O marido diz:

14) a Maria Clara COMprou CEdo o boné

situação: a Maria Clara precisa comprar um par de sapatos novos para ir a uma festa. Mas ela é conhecida por ser muito indecisa e demorar uma eternidade para escolher o mais bonito. A mãe pergunta e a irmã responde:

Q: Como a Maria Clara comprou os sapatos desta vez?

15) a Maria Clara COMprou RÁpido.

16) os sapatos, até que a Maria Clara COMprou RÁpido dessa vez.

situação: a Maria Clara adora esportes e pratica vários. A mãe pergunta e a irmã responde:

Q: Quando a Maria Clara jogou bola?

17) a Maria Clara JOgou TERça depois do almoço.

18) bola, a Maria Clara JOgou TERça depois do almoço.

situação: jogar o lixo é uma tarefa das crianças, que se revezam. A mãe pergunta e o pai responde:

Q: hoje é dia de quem colocar o lixo na rua?

19) a Maria Clara jogou ontem, hoje é a vez do João.

Situação: a Maria Clara e a Joana estão de castigo, proibidas de sair de casa. A mãe vai a um congresso e quando volta, pergunta e a empregada responde: Q: alguém me desobedeceu?

20) a Maria Clara saiu ontem. 
Situação: a mãe viaja para um congresso e deixa a filha pequena com a sogra. Quando volta pergunta e a sogra responde:

Q: a Maria Clara deu trabalho?

21) a Maria Clara chorou ontem quando você saiu, mas depois se acostumou.

Situação: há dois congressistas hospedados num hotel. O coordenador do evento, preocupado, liga para um amigo e pergunta se eles já foram, e o amigo responde: Q: alguém já foi embora?

22) a Maria Clara partiu ontem, mas o joão pedro só vai amanhã.

Situação: a Maria Clara e a Joana não gostam de comer feijão. A mãe chega do trabalho, pergunta e a empregada responde:

Q: alguma delas comeu feijão?

23) a Maria Clara comeu hoje, mas a joana não quis nem saber.

Situação: a Maria Clara e a Joana têm que comer feijão e figado todos os dias por causa de uma anemia. A mãe esteve viajando. Quando volta, pergunta e a empregada responde:

Q: elas comeram direitinho?

24) o fígado, a Maria Clara comeu hoje no almoço, mas feijão não teve jeito.

Situação: a maria clara e seus amigos estão acampando. Eles lhe arranjam um violão e pedem para ela cantar; o namorado responde.

Q: canta uma música pra gente, Maria Clara.

25) Andança, a Maria Clara cantou ontem. Não aguento mais.

26) a Maria Clara cantou ontem à noite, hoje é a vez do João.

Q: toca violão pra gente, maria clara.

27) a Maria Clara tocou ontem, hoje ela vai descansar.

situação: seu Geraldo adora jogar bingo com a família mas não pôde ir à última rodada. Ele pergunta e a esposa responde.

Q: algum de nós ganhou alguma coisa?

28) a Maria Clara jogou ontem, mas não ganhou nada. 